\title{
Motor response to apomorphine and levodopa in asymmetric Parkinson's disease
}

\author{
M Rodriguez, G Lera, J Vaamonde, M R Luquin, J A Obeso
}

\begin{abstract}
The motor responses of 14 patients with Parkinson's disease (six previously untreated and eight chronically receiving levodopa) with pronounced asymmetry in the severity of motor signs between the left and right sides of the body were studied. The effects of a short (60 minutes) and a long (16-22 hours) intravenous levodopa infusion as well as of subcutaneous apomorphine (1-6 mg bolus) were assessed. Four different tapping tests were used to measure motor function. For all pharmacological tests, the more affected side showed a shorter response duration, increased latency, and greater response magnitude than the less affected side. These differences were more pronounced in those patients receiving chronic levodopa treatment. As apomorphine is not dependent on dopamine storage capacity, these findings suggest that postsynaptic mechanisms play an important part in the origin of motor fluctuations in Parkinson's disease.
\end{abstract}

$(\mathcal{F}$ Neurol Neurosurg Psychiatry 1994;57:562-566)

Daily fluctuations in motor performance are a common and troublesome complication of chronic treatment with levodopa for Parkinson's disease. Chase's group showed that the duration of the motor response (the "on" period) to an acute levodopa challenge is inversely correlated with disease severity. It was proposed that progressive degeneration of the nigrostriatal pathway leads to a decreased storage capacity for the dopamine synthesised from exogenous levodopa. ${ }^{1-3}$ Thus the basic pathophysiological mechanism underlying motor fluctuations in Parkinson's disease could be a presynaptic defect in buffering the oscillations in plasma levodopa concentrations. ${ }^{3}$ Reduced storage capacity might be associated with higher synaptic dopamine concentrations, thus explaining the steeper dose-response curve reported in more severely affected patients. ${ }^{4}$ The relation between severity of disease and shortening of the response to levodopa has been less clear, however, in other studies ${ }^{5-7}$ throwing some doubt on the fundamental role of defective striatal dopamine storage capacity in the origin of motor fluctuations. The existence of postsynaptic dopaminergic abnormalities in severe Parkinson's disease has also been considered in view of the difficulty in keeping patients constantly "on" during prolonged levodopa infusions ${ }^{289}$ and continuous treatment with dopamine agonists such as lisuride, apomorphine, and (+)-4-propyl-9-hydroxynaphthoxazine (+PHNO). ${ }^{10-12}$ In this study we report the response to subcutaneous apomorphine boluses and prolonged and short infusions of levodopa in 14 patients with asymmetric Parkinson's disease. This approach allowed us to assess and compare the motor response induced by a presynaptically and postsynaptically acting drug in relation to disease severity without the problems in interpretation derived from peripheral pharmacokinetic modifications.

\section{Patients and methods}

PATIENTS

Fourteen patients (three females and 11 males) with asymmetric Parkinson's disease were studied. Parkinsonian signs were worse on the left side in 10 patients and the right side was more affected in four. The non-dominant side was more severely parkinsonian in eight patients. Six patients had never been treated with levodopa or any other antiparkinsonian drug (de novo) and eight showed daily motor fluctuations ("treated") after a mean 4.9 (range 2-10) years of levodopa treatment. The mean daily dose of levodopa (plus a decarboxylase inhibitor) was 856.2 (range 600-900) $\mathrm{mg}$ for the eight patients on treatment. Two patients were also on treatment with bromocriptine (20 and $25 \mathrm{mg}$ daily) and another was taking amantadine (300 $\mathrm{mg} /$ daily). Both drugs were discontinued seven days before the study. The mean duration of illness was 4.5 (range 1-4) years for the "de novo" group, and 6.5 (range 2-10) years for the treated group. Before the study the mean score on the unified Parkinson's disease rating scale (URSP) was $37 \cdot 7$ (range 26-56) for the entire group; "de novo" patients had a mean score of 31 (SD 4.7) (range 26-36) and treated patients scored $45.6(7 \cdot 9)$ (range 28-59) when "off".

PHARMACOLOGICAL TESTS

Patients were in hospital during the study and received domperidone (60 $\mathrm{mg}$ daily) from three to five days before until the conclusion of the study. All patients were informed of the purpose and potential risks of the study. Levodopa was stopped the night before the tests in the eight patients on treatment. These patients resumed their normal therapeutic and in final revised form 29 June 1993.

Accepted 5 July 1993. 
regimen immediately after the end of each test. The total period in hospital was $7-10$ days.

Levodopa (Chiesi Farmaceutica, Italy) was diluted in sterile saline ( $9 \%$ ) to a final concentration of $1 \mathrm{mg} / \mathrm{ml}$ and a $\mathrm{pH}$ of $5 \cdot 4$. Intravenous infusions were given through a forearm vein on the less affected side through a standard catheter. Apomorphine $(10 \mathrm{mg} / \mathrm{ml}$, Woelm, Germany) was given subcutaneously in the arm.

Pharmacological tests were performed in the morning in the following sequences:

(1) The minimal effective dose (MED) of subcutaneous apomorphine.

The MED was defined as the dose of apomorphine capable of reducing motor disability (unified Parkinson's disease rating scale or tapping tests) by at least $50 \%$ during $10-15$ minutes. This dose was determined for each patient on successive days starting with 0.50 $\mathrm{mg}$ of apomorphine and increasing the dose to reach the MED. The mean MED of apomorphine was 2.25 (SD 0.5) (range 1-3) mg

(2) Twice the MED of apomorphine

This was given subcutaneously to each patient.

\section{(3) Short levodopa infusion}

Intravenous levodopa was infused at a constant rate of $250 \mathrm{mg} / \mathrm{h}$ until a motor improvement of $50 \%$ in both sides was seen. The infusion was stopped at that moment. Carbidopa ( $25 \mathrm{mg}$ orally) was given three hours and one hour before starting the infusion.

(4) Prolonged levodopa infusion

A levodopa infusion at a rate of $60-100 \mathrm{mg} / \mathrm{h}$ was given for 16-22 hours. The infusion rate was adjusted to ensure that the patient remained "on" (bilaterally) until sleep time. Levodopa infusion was maintained subsequently during the night. Three patients were not "on" the next morning despite having

Figure 1 Movement capacity (expressed as \% of baseline measurements) evaluated by four different motor tasks in the more and less affected limbs of 14 patients with asymmetric Parkinson's disease. $(A)$ Response to a short ( 60 min) intravenous levodopa infusion. (B) Response to the minimal effective dose (MED) of apomorphine $(1.3 \mathrm{mg})$ given as a subcutaneous bolus. The motor responses followed a similar pattern for both tests. All four motor tasks discriminated equally well between the severities of each side.

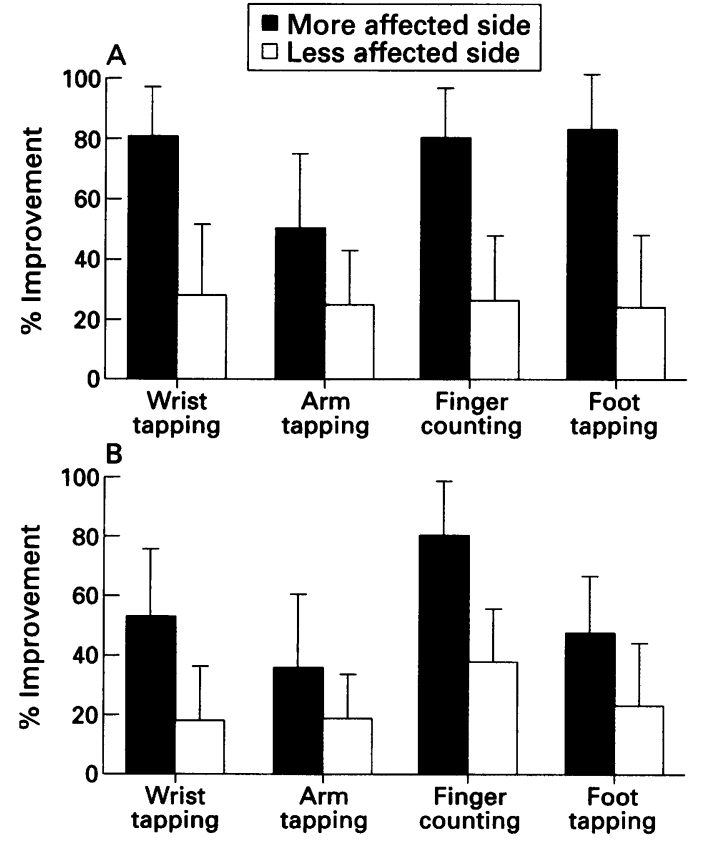

received the levodopa infusion during the night. In these instances, the levodopa infusion rate was again increased and adjusted to guarantee the "on" state for a minimum of three hours before stopping the infusion. Carbidopa (25 mg orally) was given every three hours until the end of the infusion.

\section{ASSESSMENT}

Motor function was assessed separately in the right and left sides of the body by four motor tests. Patients were sitting comfortably on a chair maintaining the trunk in an upright position and as vertical as possible. The examiner counted the number of valid movements made in 30 seconds. The tests consisted of: (a) wrist tapping (patients touched repetitively a manual digital counter placed on a table); (2) finger counting (separation of the index finger from the thumb by a minimum of $3 \mathrm{~cm}$ ); (3) arm tapping (patients tapped with the hand two points placed $30 \mathrm{~cm}$ apart in front of the subject); (4) foot tapping (repetitive foot raising in the vertical axis by at least $20 \mathrm{~cm}$ ). These four tests were applied to monitor the motor response to levodopa and apomorphine. The motor state was continuously assessed by the examiner. The motor tests were performed at baseline and every $10 \mathrm{~min}$ utes after giving drugs, or at any time during the experiment when the observer believed that an important modification in the motor state had occurred.

The following items were analysed for each patient: (a) latency to the beginning of the motor response (defined as a minimum improvement in motor capability of $25 \%$ ) in any of the motor tests; (b) The magnitude of the response (difference in motor scores between "off" and "on"; (c) The duration of the benefit ("on") defined as the interval between the beginning of the response and the return to baseline of the motor scores after giving apomorphine. For the levodopa infusions, "on" duration was counted as the time elapsed between cessation of the infusion and return to the baseline score.

A paired Student's $t$ test was used to compare the more and less affected sides. A $t$ test for unpaired comparisons was applied to analyse differences between "de novo" and treated patients. Values are expressed as means (1 SD)

\section{Results}

Each of the four tests used to monitor the motor responses followed a similar pattern and all discriminated significantly $(p<0.05)$ between the more and less affected sides in basal conditions (fig 1, A and B; fig 2). The wrist tapping test was chosen for presentation of the results to simplify comparison between sides.

MOTOR RESPONSE AND DISEASE SEVERITY $(\mathrm{n}=14)$

Latency

The "on" latency (table 1) was significantly greater in the more affected side in response 
Table 1 Comparison of the motor response to apomorphine and levodopa in 14 patients with asymmetric Parkinson's disease

\begin{tabular}{|c|c|c|c|c|}
\hline \multirow[b]{2}{*}{$\begin{array}{l}\text { Pharmacological } \\
\text { testt }\end{array}$} & \multicolumn{2}{|l|}{ More affected } & \multicolumn{2}{|l|}{ Less affected } \\
\hline & $\begin{array}{l}\text { Latency "on" } \\
(\min )\end{array}$ & $\begin{array}{l}\text { Duration "on" } \\
\text { (min) }\end{array}$ & $\begin{array}{l}\text { Latency "on" } \\
(\min )\end{array}$ & $\begin{array}{l}\text { Duration "on" } \\
\text { (min) }\end{array}$ \\
\hline $\begin{array}{l}\text { Apomorphine } \\
\text { (MED) }\end{array}$ & $22 \cdot 3(9)$ & $54 \cdot 9(30 \cdot 1)$ & $15.9(3.06)^{\star \star}$ & $90(44 \cdot 9)^{\star \star \star}$ \\
\hline $\begin{array}{l}\text { Apomorphine } \\
\text { (twice MED) }\end{array}$ & $16 \cdot 6(6 \cdot 7)$ & $74 \cdot 9(34 \cdot 2)$ & $13 \cdot 4(3 \cdot 81)$ & $120 \cdot 7(61 \cdot 3)^{\star \star}$ \\
\hline $\begin{array}{c}\text { Short levodopa } \\
\text { infusion }\end{array}$ & $28 \cdot 4(14 \cdot 8)$ & $150 \cdot 2(83 \cdot 9)$ & $40 \cdot 6(15 \cdot 3)^{\star}$ & $199 \cdot 7(71 \cdot 4)^{\star \star \star}$ \\
\hline $\begin{array}{l}\text { Long levodopa } \\
\text { infusion }\end{array}$ & - & $130(88 \cdot 8) \dagger$ & - & $191 \cdot 8(93 \cdot 4)^{\star \star}$ \\
\hline
\end{tabular}

Values are means (1 SD).

${ }^{\star} \mathrm{p}<0.05 ;{ }^{\star \star} \mathrm{p}<0.01 ;{ }^{\star \star \star} \mathrm{p}<0.001$ (differences between sides).

+ Detailed data for each test in each patient is available upon request.

†Values express the duration of the "on" after stopping the infusion.

Figure 2 Motor response elicited by subcutaneous apomorphine (mean dose $2 \cdot 25(0.5) \mathrm{mg}$ ) in 14 patients with asymmetric Parkinson's disease. Each point represents the mean value for each tapping test. Apomorphine was given at time 0 . The response had a greater magnitude but reduced duration in the most affected side.
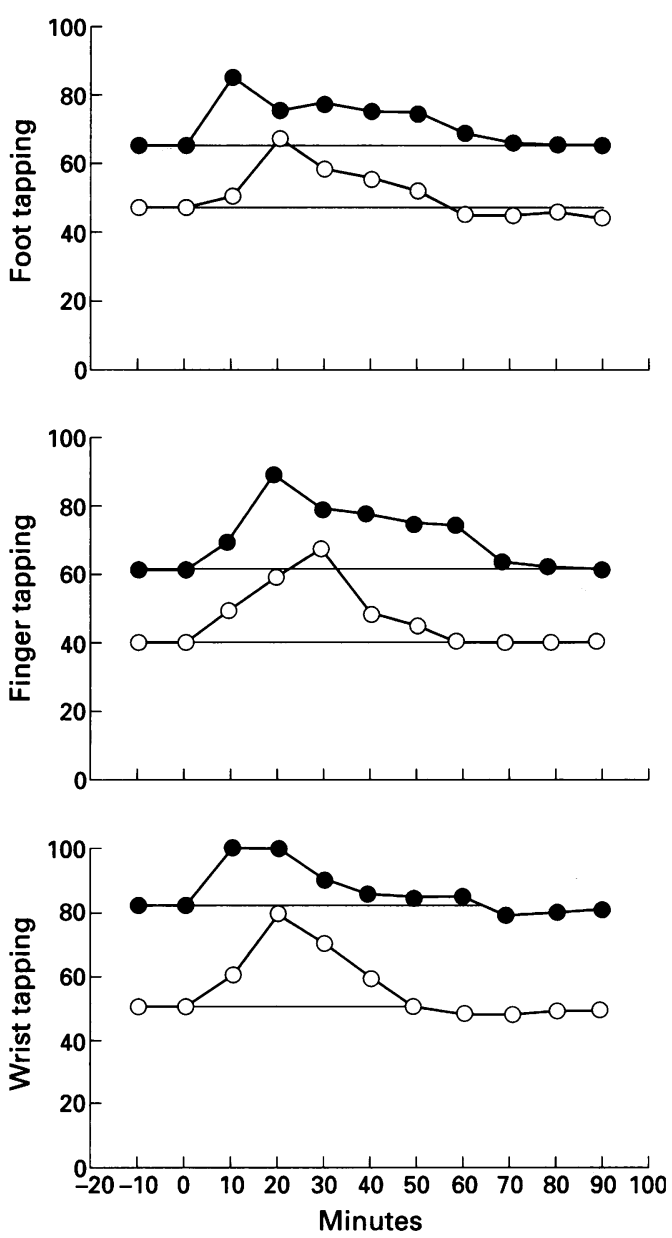

More affected side

- Less affected side

Table 2 Duration ( $\mathrm{min}$ ) of the motor response in asymmetric de novo patients $(n=6)$ and patients treated chronically with levodopa $(n=8)$

\begin{tabular}{|c|c|c|c|c|}
\hline & \multicolumn{2}{|c|}{ More affected side } & \multicolumn{2}{|c|}{ Less affected side } \\
\hline & De novo & Treated & De novo & Treated \\
\hline \multicolumn{5}{|l|}{ Severity: } \\
\hline $\begin{array}{l}\text { Pharmacological } \\
\text { tests: }\end{array}$ & $30(24)$ & $43(20 \cdot 2)$ & $84 \cdot 6(8 \cdot 5)$ & $14 \cdot 1(20 \cdot 2)$ \\
\hline Apomorphine & $74 \cdot 1(37)$ & $40 \cdot 5(11 \cdot 1)$ & $116 \cdot 6(54)$ & $70 \cdot 1(24 \cdot 7)^{\star}$ \\
\hline $\begin{array}{l}\text { Apomorphine } \\
\text { (twice MED) }\end{array}$ & $96 \cdot 6(34)$ & $53 \cdot 2(17 \cdot 5)^{\star}$ & $159 \cdot 6(61 \cdot 3)$ & $81 \cdot 6(30 \cdot 5)^{\star}$ \\
\hline
\end{tabular}

Values are means (1 SD); MED = minimal effective dose

Values are means $(1 \mathrm{SD})$

$+W$ rist tapping test. Patients touched repetitively for 30 seconds a manual digital counter placed on a table in front of them. to the MED of apomorphine $(p<0.001)$. There was no significant difference between sides after giving twice the MED of apomorphine, although the actual value was higher in the more affected side. The short levodopa infusion induced an earlier response in the more affected side (table 1). The slow infusion rate used at the beginning of the prolonged levodopa infusion precluded the measurement of "on" latency for this test.

\section{Magnitude of the response}

In all patients the magnitude of the response was greater in the more affected side $(p<$ 0.01 ) in response to both apomorphine and levodopa (fig $1 \mathrm{~A}$ and $\mathrm{B}$ ). This difference was significant $(p<0.01)$ for all pharmacological tests (fig 2).

\section{Duration}

In every patient, all four pharmacological tests described consistently showed a similar pattern-that is, the duration was longer in the less affected side than in the more affected side. Individual data are not shown for the sake of brevity but are available on personal request.

Apomorphine-The mean duration of the response $(54.9$ (SD 30.1$) \mathrm{min}$ ) in the more affected body side after subcutaneous apomorphine (MED) injection was significantly reduced ( $\mathrm{p}<0.001)$ compared with the less affected side (90 (SD 44.9) min) (table 1; fig $2)$. Twice the MED of apomorphine $(2-6 \mathrm{mg}$ ) elicited a motor response with a mean duration of 74.9 (SD 34.2 ) minutes in the more severely affected side and of 120.7 (SD 61.3) minutes in the less affected side $(\mathrm{p}<0.001$; table 1).

Short levodopa infusion-The mean duration of the motor response was significantly shorter $(\mathrm{p}<0.001)$ in the more affected side $(150.2$ (SD 83.9) $\mathrm{min}$ ) compared with the less severe side (199.7 (SD 71.4) min) (table 1).

Prolonged levodopa infusion-The duration of the antiparkinsonian action of levodopa after discontinuation of the infusion lasted for 130 (SD 88.8) minutes. In the more affected side and 191.8 (SD 93.4) minutes in the less affected side. This difference was statistically significant $(p<0.01 ;$ table 1$)$.

De novo $v$ treated patients

The magnitude of the response was greater $(p<0.01)$ in the more affected side of both de novo and treated patients. The duration of the motor response to apomorphine boluses and levodopa infusions was significantly longer in the less affected side in both de novo and treated patients (table 2). Comparison of the more affected side of de novo and treated patients did not reveal statistically significant differences in the tapping tests (table 2). Similar results were found for the less affected side suggesting a similar degree of parkinsonism for each side in both groups of patients. The magnitude of the response was also similar (fig 2) but the duration of the response to the pharmacological tests was shorter in treated patients (table 2; fig 3). 


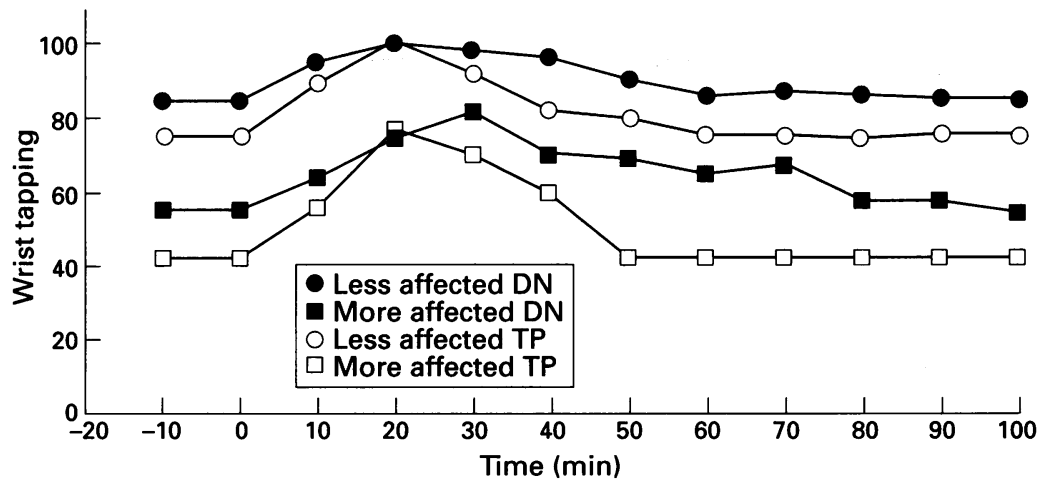

Figure 3 Comparison of the improvement elicited by an intravenous bolus of apomorphine on the more and less affected sides of eight treated patients (TP) and six de novo (DN) patients. The response is shortest in the more affected side of TP and longest in the less affected side of DN patients.

\section{Discussion}

Studies of pathology and PET scan indicate that clinical asymmetry of motor signs in Parkinson's disease reflects differences in the degree of degeneration of the substantia nigra and striatal dopamine loss. ${ }^{6}{ }^{13}$ The study of patients with asymmetric disease allowed us to compare the effect of different severity of disease (dopaminergic denervation) upon the motor response in the same subjects and exclude confounding factors such as duration of levodopa treatment, duration of disease and problems of peripheral kinetics. We found a highly significant correlation between severity of parkinsonism and latency, magnitude, and duration of the motor response. Thus the more affected side showed a greater magnitude of improvement and a shorter response duration. This relation occurred and was maintained when the same patients were challenged with apomorphine, a short levodopa infusion, or a long levodopa infusion. We therefore confirm the results of previous studies with levodopa infusions as a test regarding the shortening of the response ${ }^{12}$ and increasing magnitude ${ }^{14}$ with greater severity of disease and extend the findings to apomorphine.

The results presented here are at variance with the findings of Kempster et $a l^{6}$ who described a similar response duration to levodopa (250/25 mg orally) in both sides of patients with asymmetric disease. Differences in the method used to quantify the motor response during the pharmacological tests and in the severity of the patients may account for this discrepancy. Admittedly, measuring drug-induced responses in milder parkinsonian patients is not an easy task. We thus used four different motor tests, which assessed movement capacity in different body parts, and consistently found a shortening of the response in the more affected body side. These tapping tests are well known to be more discriminatory than the general scales usually applied to evaluate Parkinson's disease. Furthermore, it is unlikely that variations in the assessment of the duration of the motor response would always go in the same direction - that is, the more affected side consistently showing a shorter response in every patient and for all pharmacological tests. We did not take into consideration other clinical signs, such as tremor or dyskinesias (in treated patients), because they are very sensitive (and extremely variable) to uncontrollable factors such as anxiety, tiredness, and degree of mental and physical activity. In conclusion, we do not believe that our method was either insensitive for the purpose of the study or biased towards underestimating the duration of response in the more affected side. Indeed, before the study we had expected to find similar results with levodopa to those of Kempster et $a l^{6}$ and differences in the response to apomorphine, reflecting the importance of postsynaptic mechanisms in the pathophysiology of motor fluctuations. It may be that in the more severe patients studied by Kempster et $a l^{6}$ the response to levodopa, which presumably reflects mainly presynaptic mechanisms, ${ }^{34}$ was more similar due to a lesser degree of asymmetry. Whether or not this interpretation is correct might be tested in future studies.

The major finding of this study is that the correlation between severity of disease and motor response was similar for apomorphine and levodopa (both short and prolonged infusions). The decline in motor improvement after stopping the long levodopa infusion may reflect presynaptic dopamine storage. ${ }^{12}$ It follows that a reduced storage capacity should be accompanied by a shorter response after discontinuation of the infusion, as in fact occurred in this and previous studies. ${ }^{12} \mathrm{On}$ the other hand, decreased storage capacity would lead to enhanced dopamine disposition $^{4}$ after a bolus of levodopa, which should provoke a greater improvement and also a longer response. This was not the case in the patients of Gancher et $a l^{5}$ or in our patients, suggesting that dopamine storage capacity is not the only factor involved in the origin of motor fluctuations. Indeed, our results with apomorphine strongly indicate a paramount role of postsynaptic mechanisms in the origin of motor fluctuations in Parkinson's disease. Apomorphine is a direct acting dopamine agonist (D-1 and D-2 receptors) and is capable, by itself, of reversing parkinsonism. Apomorphine does not require biotransformation to be active and is not stored in the brain. ${ }^{15}$ Accordingly, the response to apomorphine essentially reflects the degree of striatal dopaminergic responsiveness mainly as a consequence of denervation. The nature and intimate characteristics of the changes induced by the loss of nigrostriatal dopaminergic activity are not clear. In untreated patients with Parkinson's disease there seems to be hypersensitivity of D-2 receptors ${ }^{16} 17$ in keeping with the findings in animals with nigrostriatal lesions. ${ }^{18}$ Dopamine (D-2) receptor density remains within normal values despite disease progression. ${ }^{19}$ The data concerning D-1 receptors are still highly controversial. Different studies have reported normal, reduced, or increased activity and number of D-1 receptors in the striatum of patients with Parkinson's disease. ${ }^{20-22}$ One suggested possibility is that motor complications could be 
more related to pathological modifications in the affinity state (high-low) of dopamine receptors. ${ }^{192324}$ In this regard, Hornykiewicz's group has recently described sensitisation of D-1 striatal receptors in rats with a 6-hydroxydopamine-induced lesion, monkeys treated with 1-methyl-1-4-phenyl-1,2,3,6-tetrahydropyridine, and in eight patients with Parkinson's disease. ${ }^{25} 26$ This alteration is not believed to be simply due to up-regulation of D-1 receptors but to alteration of the signal transduction mechanism controlling adenylyl cyclase activity. ${ }^{25}{ }^{26}$ It is conceivable therefore, that denervation-induced pathological modifications of the affinity state and also of the relative proportion of $\mathrm{D}-1 / \mathrm{D}-2$ striatal receptors could be directly implicated in the origin of the short duration response in Parkinson's disease. It was noted that acute apomorphine and levodopa treatment was accompanied by a short duration response in both de novo and treated patients. This finding indicates that the mechanics underlying the short duration response and by extension, motor fluctuations, are qualitatively similar in both groups. ${ }^{24}{ }^{27}$ Chronic levodopa treatment probably aggravates this phenomenon, particularly by reducing the duration of the response.

In conclusion, the findings suggest that the degree of substantia nigra lesion and the consequent dopaminergic deficit govern the characteristics of the response to acute challenge with potent dopaminergic drugs. The main mechanism subserving daily motor fluctuations in Parkinson's disease may not be defective storage of dopamine (from exogenous levodopa) but modifications in striatal responsiveness.

Ms M Mar López, Isabel Sánchez, and Mrs Carol Elsden prepared this article for publication. Chiesi Farmaceutica (Italy) kindly donated levodopa for intravenous use.

1 Fabbrini G, Mouradian MM, Juncos J, Schlegel J, Mohr E, Chase TN. Motor fluctuations in Parkinson's disease: central pathophysiological mechanisms. Part I. Ann central pathophysiological

2 Mouradian MM, Juncos JL, Fabbrini G, Schlegel J, Bartko JJ, Chase TN. Motor fluctuations in Parkinson's disease: central pathophysiological mechanisms. Part II. Ann Neurol 1988;24:372-8.

3 Mouradian MM, Chase TN. Central mechanisms and levodopa response fluctuations in Parkinson's disease. Clin Neuropharmacol 1988;11:378-85.

4 Wooten GF. Progress in understanding the pathophysiology of treatment-related fluctuations in Parkinson's disease. Ann Neurol 1988;24:363-5.

5 Gancher ST, Nutt JG, Woodward W. Response to brief levodopa infusions in parkinsonian patients with and without motor fluctuations. Neurology 1988;38:712-6.
6 Kempster PA, Gibb WR, Stern GM, Lees AJ. Asymmetry of substantia nigra neuronal loss in Parkinson's disease and its relevance to the mechanisms of levodopa-related motor fluctuations. $\mathcal{F}$ Neurol Neurosurg Psychiatry 1989; 52:72-6.

7 Horstink NWIM, Zijilmans JCM, Pasmar JW, Berger HSC, Korten JJ, Van't Hoj MA. Which risk factors predict the levodopa response in fluctuating Parkinson's disease? Ann Neurol 1990;27:537-43.

8 Marion MH, Stocchi F, Quinn NP, Jenner P, Marsden CD. Repeated levodopa infusions in fluctuating patients with Parkinson's disease: clinical and pharmacokinetic wata. Clin Neuropharmacol 1986;9:165-81.

9 Hardie RI, Lees AJ, Stern GM. "On-Off" fluctuations in Parkinson's disease: a clinical and neuropharmacological Parkinson's disease: a clinical and
study. Brain 1984;107:487-506.

10 Vaamonde J, Luquin MR, Obeso JA. Subcutaneous lisuride infusion in Parkinson's disease. Brain 1991;114 601-14.

11 Stibe CMH, Kempster PA, Lees AJ. Subcutaneous apomorphine in parkinsonian on-off oscillations. Lance 1988;i:403-6.

12 Grandas F, Lera G, Rodriquez M, Mena MA, Garcia de Yebenes J, Obeso JA. Continuous versus pulsatile dopaminergic stimulation in Parkinson's disease. Neurology 1990;40(suppl 1):262.

13 Leenders KL, Salomon EP, Tyrrell P, et al. The nigrostriatal dopaminergic system assessed "in vivo" by positron patients with Parkinson's disease. Arch Neurol 1990;47: patients

14 Nutt JG, Carter JH, Woodward WR, Gancher ST Pharmacodynamics of chronic l-dopa administration. Pharmacodynamics of chronic

15 Gancher ST, Woodward WR, Boucher B, Nutt JG Peripheral pharmacokinetics of apomorphine in humans. Ann Neurol 1989;26:232-8.

16 Perlmutter JS, Kilbourn MR, Raichle ME, Welch MJ MPTP-induced up-regulation of in vivo dopaminergic radioligand-receptor binding in humans. Neurology 1987;37:1575-9.

17 Agid Y, Javoy-Agid F, Rubierg M. Biochemistry of neurotransmitters in Parkinson's disease. In: CD Marsden, $S$ Fahns, eds. Movement disorders. London: Butterworths, 1987:166-230.

18 Ungerstedt V. Postsynaptic supersensitivity after 6hydroxydopamine induced-degeneration of the nigrostriatal dopamine system. Acta Physiol Scand 1971;367: 69-93.

19 Guttman M, Seeman P, Reynolds GP, Riederer P Jellinger K, Tourtelotte WW. Dopamine D2 receptor Jellinger $\mathrm{K}$, Tourtelotte WW. Dopamine D2 receptor Ann Neurol 1986;19:487-92.

20 Pimoulee C, Schomemaker H, Reynolds GP, Langer SZ (3-H) SCH 23390 labeled 01 dopamine receptors are unchanged in schizophrenia and Parkinson's disease. Eur $\mathcal{F}$ Pharmacol 1985;114:235-7.

21 Raisman R, Cash R, Ruberg M, Javoy Agid F, Agid Y. Binding of $(3 \mathrm{H}) \mathrm{SCH} 23390$ to 01 receptors in the putamen of control and parkinsonian subjects. Eur Pharmacol 1985;113:467-8.

22 Shibuya $M$. Dopamine sensitive adenylate cyclase activity in the striatum of Parkinson's disease. $\mathcal{F}$ Neural Transm 1979;44:287-92.

23 Fahns S. Fluctuations of diability in Parkinson's disease: pathophysiological aspects. In: CD Marsden, $S$ Fahn, pathophysiological aspects. In: CD Marsden, S Fahn, Eds. M. 45.

24 Obeso JA, Grandas F, Vaamonde J, Luquin MR, Artieda $\mathrm{J}$, Lera $\mathrm{G}$, et al. Motor complications associated with chronic levodopa therapy in Parkinson's disease. Neurology 1989;39(suppl 2):11-9.

$25 \mathrm{Pifl} \mathrm{CH}$, Reither $\mathrm{H}$, Hornykiewicz O. Functional sensitization of striatal dopamine D1 receptors in the 6-hydroxydopamine-lesioned rat. Brain Res 1992;572:87-93

26 Pifl $\mathrm{CH}$, Nanoff $\mathrm{CH}$, Schingnitz G, Schutz W, Hornykiewicz G. Sensitization of dopamine-stimulated adenylyl cyclase in the striatum of 1-methyl-1-4-phenyl1,2,3,6-tetrahydropyridine-treated rhesus monkeys and patients with idiopathic Parkinson's disease. $f$ Neurochem 1992;58:1997-2003.

27 Lees AJ. The "on-off" syndrome. I Neurol Neurosurg Psychiatry. 1989;52:26-31. 